\title{
POPULAÇÃO DE PLANTAS E ESPAÇAMENTO ENTRE LINHAS DO FEIJOEIRO IRRIGADO. II: RENDIMENTO DE GRÃOS E COMPONENTES DO RENDIMENTO
}

\author{
PLANT POPULATION AND ROW SPACING FOR IRRIGATED DRYBEAN \\ II: GRAIN YIELD AND YIELD COMPONENTS
}

\author{
Sidnei Osmar Jadoski ${ }^{1}$ Reünar Carlesso $^{2}$ Dolores Woischick ${ }^{3}$ \\ Mirta Teresinha Petry ${ }^{4}$ Zoimir Frizzo ${ }^{5}$
}

\section{RESUMO}

O objetivo deste experimento foi avaliar o efeito de diferentes populações de plantas e espaçamentos entre linhas de cultivo na produção de massa seca, rendimento de grãos $e$ componentes do rendimento da cultura do feijoeiro irrigado. $O$ experimento foi conduzido no ano agrícola 1997/1998, em área do Departamento de Engenharia Rural da Universidade Federal de Santa Maria, RS. A cultivar de feijão preto BR-FEPAGRO 44 Guapo brilhante, habito de crescimento indeterminado (tipo II), foi submetida a três populações de plantas $(175,250$ e 325 mil plantas $\left.h^{-1}\right)$ e três espaçamentos entre linhas de cultivo $(35,50 e$ $65 \mathrm{~cm})$. Utilizou-se o delineamento experimental inteiramente casualizado, bifatorial, com quatro repetições. Irrigações por aspersão foram aplicadas quando a evapotranspiração máxima da cultura, estimada a partir da evaporação do tanque classe "A", indicava um valor acumulado de $25 \mathrm{~mm}$. Os resultados demonstraram que as diferentes populações de plantas $e$ espaçamentos entre linhas de cultivo não ocasionaram alterações no rendimento de grãos e massa de mil sementes. No entanto, o número de sementes por vagem $e$ de vagens por planta aumentaram com a redução na população de plantas. Na fase do enchimento de grãos, a redução do espaçamento entre linhas de cultivo aumentou a massa seca da parte aérea das plantas. A cultivar de feijoeiro, BR-FEPAGRO 44 - Guapo brilhante apresenta elevada plasticidade dos componentes do rendimento, havendo compensação no rendimento de grãos nas menores populações de plantas com aumento da produção por planta.

Palavras-chave: irrigação, sistema de cultivo, feijão, evapotranspiração.

\section{SUMMARY}

The objective of this experiment was to evaluate the effect of different plant populations and row spacing on dry matter accumulation, grain yield and yield components of irrigated drybean. The experiment was conducted during the $1997 / 98$ growing season in the experimental field of the Rural Engineering Department of the Federal University of Santa Maria, Santa Maria - RS, Brayl. The cultivar BR-FEPAGRO 44 Guapo brilhante, (type II) was submitted to three plant populations $\left(175,250\right.$ and 325 thousand plants $\left.\mathrm{a}^{-1}\right)$ and three row spacing $(35,50$ and $65 \mathrm{~cm})$. A factorial completely randomized design was used with four replications. Sprinüer irrigations were appiied when maximum crop evapofranspiration, determined based on class A evaporation pan, indicated na accumulated value of $25 \mathrm{~mm}$. Results demonstrated that the different plant populations and row spacing did not affect grain yield and grain weight. However, the number ofseeds per legume and legumes per plant increased as plant population decreased. The reduction in row spacing increased shoot dry matter during grain filling period. The cultivar BR-FEPAGRO 44 - Guapo brilhante presented great plasticity of grain yield components mainly because the reduction in plant population resulted in higher grain yield of individual plants.

Key words: irrigation, crop system, drybean, evapotranspiration.

\section{INTRODUÇÃO}

O aprimoramento das técnicas de manejo das plantas nas áreas de cultivo do feijoeiro

\footnotetext{
${ }^{1}$ Engenheiro Agrônomo, MSc., Estudante do Programa de doutorado em Energia na Agricultura, Universidade Estadual Paulista (UNESP), Botucatu - SP.

${ }^{2}$ Engenheiro Agrônomo, PhD., Bolsista CNPq, Professor Títular do Departamento de Engenharia Rural, Universidade Federal de Santa Maria (UFSM), 97105-900, Santa Maria - RS. E-mail: carlesso@ccr.ufsm.br. Autor para correspondência.

${ }^{3}$ Engenheiro Agrônomo, Programa de Mestrado em Agronomia, UFSM.

${ }^{4}$ Engenheiro Agrônomo, Programa de Mestrado em Engenharia Agrícola, UFSM.

${ }^{5}$ Acadêmico do Curso de Agronomia da UFSM, Bolsista PIBIC.
} 
constitui-se em fator preponderante para a elevação do rendimento de grãos dessa cultura. Dentre as técnicas de manejo recomendadas para a cultura, GRAFTON et $\boldsymbol{a l}$. (1988) destacam a adequação da população e do espaçamento de plantas como importantes para uma melhor utilização da água, nutrientes e radiação solar. Segundo ADAMS \& WEAVER (1998), a adequação da população e o espaçamento entre plantas promovem um ajuste das relações ambiente-planta para a expressão máxima da produtividade.

De acordo com SANDOVAL-AVILA $\boldsymbol{e t}$ al. (1994), embora seja elevado o número de publicações sobre estudos de população e espaçamento de plantas de feijoeiro, ainda não existe consenso para o manejo correio desses parâmetros. As respostas das plantas de feijão às alterações nas condições de competição por recursos ambientais, como radiação solar, água e nutrientes, geradas por modificações na população e espaçamento de plantas, apresentam estreita relação com o tipo e hábito de crescimento da cultivar (NIENHUIS \& SINGH, 1985). Segundo ALMEIDA \& SANGOI (1994), a cultivar de feijão através do seu hábito de crescimento e da capacidade de compensar o espaço disponível, é fator primordial a ser considerado na definição da população e espaçamento de plantas adequado.

ADAMS (1967) descreve que a estabilização do rendimento de grãos é proporcionada pela interdependência entre os componentes do rendimento, sendo a competição entre as plantas intensificada à medida que ocorrem limitações nos recursos ambientais disponíveis. Para COSTA et al. (1983), a plasticidade dos componentes do rendimento apresentada por algumas cultivares de feijão, frente a diferentes condições ambientais, devido a variações no espaçamento e população de plantas, pode facilitar a manutenção de um nível mais estável do rendimento de grãos quando existir o efeito de compensação entre eles.

Analisando resultados de vários experimentos, KUENEMAN et al. (1979) verificaram que para uma mesma população de plantas o rendimento de grãos do feijoeiro aumenta para espaçamentos equidistantes entre plantas, isto é, reduzindo o espaçamento entre linhas de cultivo e aumentando a distância entre as plantas na linha. GRAFTON et al. (1988) salientam que, para cultivares de feijoeiro de crescimento indeterminado, o rendimento de grãos foi mais afetado pela distância entre plantas na linha do que pelo espaçamento nas entrelinhas de cultivo. Entretanto, FRONZA et al. (1994), utilizando duas cultivares de feijoeiro do tipo II, com espaçamentos entre linhas variando de 20 a $50 \mathrm{~cm}$, observaram que a máxima eficiência técnica para o rendimento de grãos ocorreu no espaçamento de $33 \mathrm{~cm}$ entre linhas.
Para a maioria das cultivares de feijão, o aumento da população ocasiona reduções no rendimento de grãos por planta, número de vagens por planta e de grãos por vagem, sendo que a massa de mil sementes apresenta comportamento inverso. Resultados de experimentos demonstram que o número de vagens por planta do feijoeiro diminui com o aumento da população, seja pela variação do espaçamento entre linhas (BENNETT et al., 1977), das plantas na linha (EDJE et al., 1975) ou de ambos (THOMÉ \& WESTPHALEN, 1988). A acumulação de massa seca depende da interceptação da radiação solar pela cultura e da capacidade de conversão em biomassa. Assim, para uma maior produção de massa seca, o espaçamento de plantas na linha e nas entre linhas mais eficiente para interceptação de energia é o que proporciona maior cobertura superficial durante o ciclo de desenvolvimento da cultura (SHIBLES \& WEBER, 1966).

Nos últimos anos, progressivo aumento nas áreas irrigadas com a cultura do feijão foi observado na região Sul do Brasil, principalmente devido ao elevado potencial produtivo da cultura e do preço de comercialização. Nessa região, normalmente ocorrem períodos de déficit hídrico para o feijão cultivado na safra e safrinha, resultando em redução acentuada no rendimento de grãos. O recente aumento das áreas irrigadas, associada à utilização de novas variedades de feijão, requer o estabelecimento de um manejo adequado da cultura e do sistema de irrigação para maximizar o lucro líquido da atividade agrícola. Assim, este experimento foi desenvolvido com o objetivo de avaliar o efeito de diferentes populações de plantas e espaçamentos entre linhas de cultivo sobre a produção de massa seca, rendimento de grãos e componentes do rendimento da cultura do feijoeiro irrigado por aspersão.

\section{MATERIAL E MÉTODOS}

O experimento foi conduzido em área experimental do Departamento de Engenharia Rural, da Universidade Federal de Santa Maria - RS, na latitude de $29^{\circ} 41^{\prime} 24^{\prime}$ ' $S$ e longitude de $53^{\circ} 48^{\prime} 42^{\prime}$ ' $\mathrm{W}$. O clima predominante na região é o "Cfa", subtropical úmido, de acordo com a classificação climática de Köeppen (MORENO, 1961). O solo do local é de textura arenosa, classificado como Podzólico vermelho-amarelo, pertencente à unidade de mapeamento São Pedro.

A adubação foi realizada de acordo com a análise química do solo e seguindo recomendações da COMISSÃO DE FERTILIDADE PARA SOLOS DO RS e SC (1995) para a cultura do feijoeiro. Foram aplicados $100 \mathrm{~kg} \mathrm{~N}$ há ${ }^{-1}, 10 \mathrm{~kg} \mathrm{P}_{2} \mathrm{O}_{5}$ há $^{-1}$ e $40 \mathrm{~kg}$ $\mathrm{K}_{2} \mathrm{O}$ há $^{-1}$, na forma de ureia, super fosfato triplo e 
cloreto de potássio, respectivamente. O nitrogénio foi aplicado $1 / 3$ na semeadura e o restante dividido em duas aplicações, realizadas aos 25 e 40 dias após a emergência das plantas (DAE).

A cultivar de feijão preto BR-FEPAGRO 44 - Guapo brilhante, de crescimento indeterminado (tipo II) foi semeada no dia 17 de outubro de 1997. $\mathrm{O}$ cultivo foi realizado em sucessão à cultura do milho, em sistema de plantio direto. A cultura da ervilhaca (Vicia sativa L.) foi utilizada para cobertura do solo na entresafra. A emergência das plantas ocorreu seis dias após a semeadura, quando, aproximadamente, $50 \%$ das plântulas haviam emergido.

O experimento foi conduzido no delineamento experimental inteiramente casualizado, bifatorial (3 x 3$)$, com quatro repetições. As populações de plantas utilizadas foram 175,250 e 325 mil plantas há ${ }^{-1}$ e os espaçamentos entre linhas de cultivo foram 35,50 e $65 \mathrm{~cm}$. Esses valores são os que normalmente são utilizados pêlos produtores (amplitude mínima e máxima). As unidades experimentais apresentavam dimensões de 3 x 4 metros e as linhas de cultivo foram orientadas longitudinalmente no sentido Leste-Oeste.

A irrigação foi realizada por um sistema de aspersão convencional fixo. Irrigações foram aplicadas quando a evapotranspiração máxima da cultura indicava um valor acumulado de $25 \mathrm{~mm}$. A estimativa da evapotranspiração de referência foi obtida com base na evaporação do tanque classe "A" e do coeficiente de tanque. A evapotranspiração máxima da cultura foi determinada utilizando-se os valores estimados da evapotranspiração de referência e do coeficiente de cultura, propostos por DOORENBOS \& KASSAN (1979).

A massa seca da parte aérea das plantas foi determinada aos $24,35,46,58$ e 66 DAE, através da coleta das plantas de uma área de $0,35 \mathrm{~m}^{2}$ em cada parcela, que após separadas em folhas, hastes, ramos e vagens, foram colocadas em estufa a $60^{\circ} \mathrm{C}$, durante 72 horas. A colheita do experimento foi realizada aos 89 DAE. O rendimento de grãos foi determinado pela colheita das plantas em uma área útil de $5,0 \mathrm{~m}^{2}$ na parte central de cada parcela. Foram avaliados os seguintes componentes do rendimento: número de vagens por planta, número de sementes por vagem e massa de mil sementes. A massa de mil sementes foi determinada com a utilização de cinco subamostras de 100 sementes, em cada parcela, cujas médias obtidas foram extrapoladas para 1000. Tanto este parâmetro, como o rendimento de grãos, foram avaliados com umidade corrigida para
$13 \%$. O número de vagens por planta foi obtido por contagem das vagens que apresentavam mais de uma semente e, no mínimo, $2,5 \mathrm{~cm}$ de comprimento. $\mathrm{O}$ número de grãos por vagem foi quantificado pela razão entre o número de grãos e o número de vagens da planta.

A análise estatística foi realizada utilizando-se o programa Statistical Analysis System (SÃS). Determinaram-se a análise da variância e regressão dos resultados, em nível de significância de $5 \%$.

\section{RESULTADOS E DISCUSSÃO}

A evapotranspiração máxima acumulada durante o ciclo de desenvolvimento das plantas, dos 14 aos 94 DAE foi de $281,5 \mathrm{~mm}$. Nesse período, o total de precipitação pluvial ocorrido foi de $574 \mathrm{~mm}$, tendo sido aplicados $132 \mathrm{~mm}$ de água, através de cinco irrigações de aproximadamente $25 \mathrm{~mm}$ (Figura 1). O montante das precipitações pluviais ocorrido no período foi elevado devido à ocorrência do fenómeno El Nino. No entanto, as precipitações foram irregularmente distribuídas, coincidindo a época de menor ocorrência das precipitações e elevada insolação, com a fase de maior desenvolvimento do dossel vegetativo (35 a 60 DAE).

O número de vagens por planta, número de sementes por vagem e massa de mil sementes

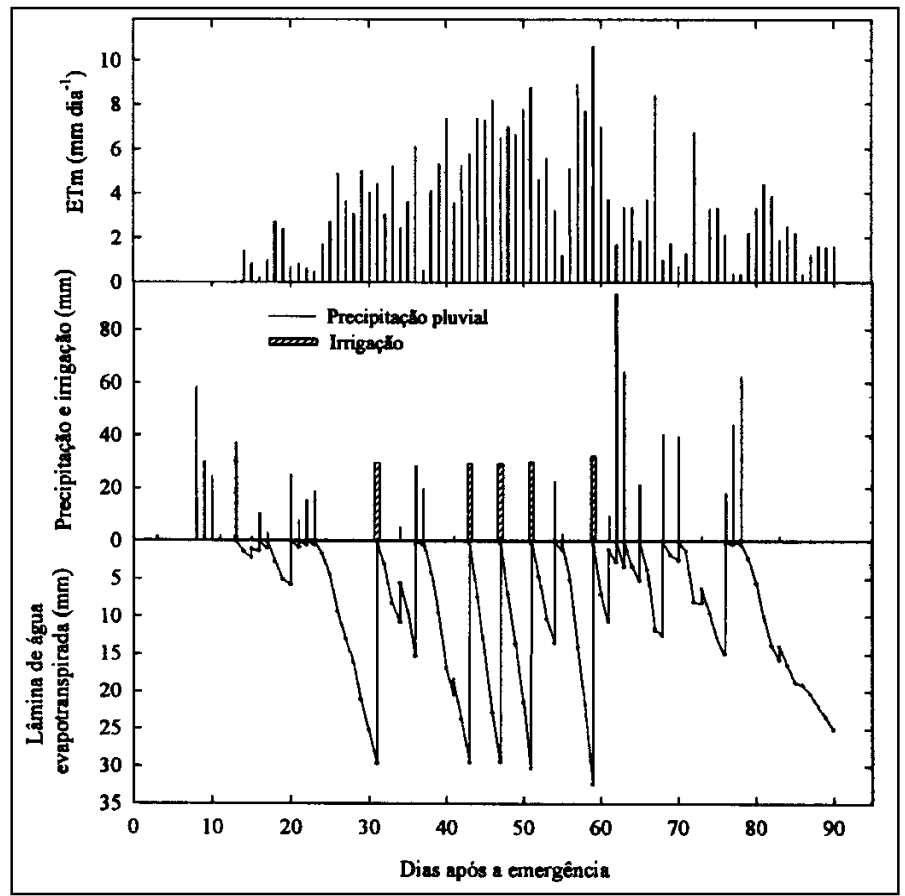

Figura 1 - Evapotranspiração máxima, precipitação, irrigações aplicadas e evapotranspiração acumulada do feijoeiro submetido a diferentes populações e espaçamentos entre linhas. Santa Maria - RS, 1988. 
(componentes do Tabela 1 - Quadrados médios da análise da variância para o número de vagens por planta, número de semenrendimento de grãos) não foram afetados pelo espaçamento entre linhas de cultivo (Tabela 1). Esses resultados diferem dos obtidos por SILVEIRA et al. (1988), STONE \& PEREIRA (1994a) e ARF et al. (1996), que verificaram aumentos lineares no número de vagens por planta com o aumento do espaçamento entre linhas. Entretanto, tes por vagem, rendimento de grãos, massa de mil sementes e massa seca (MS) do feijoeiro sob diferentes populaçōes de plantas e espaçamentos entre linhas de cultivo. Santa Maria - RS, 1998.

\begin{tabular}{|c|c|c|c|c|c|c|c|}
\hline $\begin{array}{l}\text { Causas de } \\
\text { variação }\end{array}$ & GL & $\begin{array}{l}\text { Número de } \\
\text { vagens }\end{array}$ & $\begin{array}{l}\text { Sementes } \\
\text { por vagem }\end{array}$ & $\begin{array}{l}\text { Rendimento } \\
\text { de grãos }\end{array}$ & $\begin{array}{c}\text { Massa de mil } \\
\text { sementes }\end{array}$ & $\begin{array}{l}\text { MS hastes } \\
\text { e ramos ** }\end{array}$ & $\begin{array}{c}\text { MS folhas } \\
\text { ** }\end{array}$ \\
\hline População (Pop) & 2 & 125,78 & 1,1452 & 23105,21 & 494,9611 & 10,293 & 23,2220 \\
\hline Linear & 1 & $246,91^{*}$ & $2,1720 *$ & $29039,90 \mathrm{~ns}$ & $470,6432 \mathrm{~ns}$ & $14,161 \mathrm{~ns}$ & 209,389 ns \\
\hline Quadrática & 1 & $4,661 \mathrm{~ns}$ & $0,1184 \mathrm{~ns}$ & $17170,51 \mathrm{~ns}$ & $519,2790 \mathrm{~ns}$ & $6,4820 \mathrm{~ns}$ & $255,003 \mathrm{~ns}$ \\
\hline Espaçamento (Esp) & 2 & 7,7346 & 0,2778 & 134527,0 & 102,4232 & 159,42 & 289,358 \\
\hline Linear & 1 & $6,324 \mathrm{~ns}$ & $0,0026 \mathrm{~ns}$ & $268776,4 \mathrm{~ns}$ & $102,0525 \mathrm{~ns}$ & $309,60 *$ & $542,450 *$ \\
\hline Quadrática & 1 & $9,145 \mathrm{~ns}$ & $0,5530 \mathrm{~ns}$ & $277,5761 \mathrm{~ns}$ & $102,7939 \mathrm{~ns}$ & $9,2450 \mathrm{~ns}$ & $36,2660 \mathrm{~ns}$ \\
\hline Interação Pop x Esp & 4 & $11,03 \mathrm{~ns}$ & $0,1108 \mathrm{~ns}$ & $112552,4 \mathrm{~ns}$ & $178,0481 \mathrm{~ns}$ & $117,03 \mathrm{~ns}$ & $149,782 \mathrm{~ns}$ \\
\hline Resíduo & 27 & 7,2839 & 0,6532 & 224769,4 & 223,2647 & 71,898 & 92,5410 \\
\hline CV\% & & 2,8 & 14,8 & 25,3 & 8,3 & 19,9 & 12,2 \\
\hline
\end{tabular}

*= Significativo em nivel de $5 \%$ de probabilidade;

$\mathrm{GL}=$ Graus de liberdade;

** = Determinação realizada aos $66 \mathrm{DAE}$;

$\mathrm{CV}=$ Coeficiente de variação.

respostas

significativas do número de vagens por planta e de sementes por vagem foram verificadas em relação à população de plantas. Não houve efeito de interação entre os fatores população de plantas e espaçamento entre linhas de cultivo sobre esses parâmetros (Tabela 1).

O número de vagens por planta aumentou linearmente com a redução da população de plantas (Figura 2). Esses resultados concordam com os observados por WESTERMANN \& CROTHERS (1977), SILVEIRA $\boldsymbol{e t}$ al. (1988), ALCÂNTARA $\boldsymbol{e}$ al. (1991) e STONE \& PEREIRA (1994a). O número de vagens por planta é o componente de produção da cultura do feijão mais afetado por variações na população de plantas (ADAMS, 1967; LUCAS \& MILBOURN, 1976; 20 BENNETT et al., 1977 e ARF et al., 1992).

A redução da população de plantas de 325.000 para 135.000 plantas há $^{-1}$ aumentou o número de sementes por vagem (Figura 2). Resultados semelhantes, para a cultura do feijão, também foram observados por BENNET et al. (1977), THOMÉ \& WESTPHALEN (1988), ALCÂNTARA $\boldsymbol{e t}$ al. (1991) e STONE \& PEREIRA (1994a). Segundo GOULDEM (1976), a competição por luz e fotoassimilados propiciada pelo aumento da população de plantas do feijoeiro, pode ocasionar abortamento de flores e chochamento das vagens, com redução do número de sementes produzidas.

A falta de efeito significativo de população e espaçamento entre linhas sobre o peso de 1000 sementes

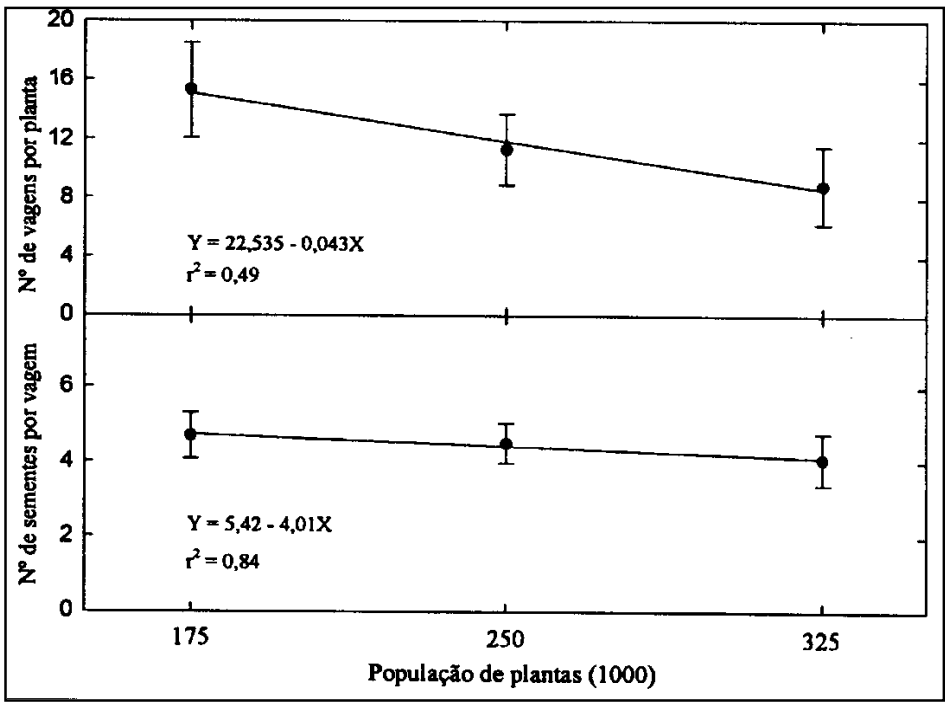

Figura 2 - Número de vagens por planta e de sementes por vagens de feijoeiro em relação às diferentes populações de plantas. As barras verticais representam o desvio-padrão. Santa Maria - RS, 1988. 
mais facilmente afetado pelo aumento da população, devido ao ambiente de competição, seguindo-se o número de sementes por vagem e, por último, a massa das sementes.

Populações de plantas de 175.000 a 325.000 plantas ha' e espaçamentos de 35 a $65 \mathrm{~cm}$ entre linhas não ocasionaram diferença significativa no rendimento de grãos da cultura do feijoeiro (Tabela 1). WESTERMANN \& CROTHERS (1977) também não observaram efeito da população de plantas sobre o rendimento de grãos da cultura do feijoeiro do tipo II. Esses autores, além de COSTA et al. (1983) e ABREU (1989), sugerem que o aumento do rendimento de grãos com a elevação na população é normalmente mais observado em cultivares de feijoeiro do tipo I (hábito de crescimento determinado).

A plasticidade do rendimento de grãos apresentada por cultivares de feijoeiro do tipo II, em relação à variação na população e espaçamento entre linhas de cultivo, foi também observada por VIEIRA (1968), para espaçamentos de 40 a $50 \mathrm{~cm}$ entre linhas e populações que variaram de 320 mil a um milhão de plantas há ${ }^{-1}$. DARIVA et al. (1975) também observaram resultados semelhantes com populações entre 125 mil a um milhão de plantas há ${ }^{-1}$ e espaçamentos de 20 a $80 \mathrm{~cm}$ entre linhas. Esses autores, além de FARIA \& KRANTZ (1982), ALCÂNTARA et al. (1991) e ARF et al. (1992) não observaram efeito da população de plantas sobre o rendimento de grãos do feijoeiro, assim como STONE \& PEREIRA (1994a) e ARF et al. (1996) para espaçamentos entre linhas de cultivo.

A análise estatística dos resultados de massa seca das folhas, hastes e ramos, vagens e massa seca total da parte aérea das plantas não indicou diferenças significativas nas determinações realizadas no período de 24 a 58 DAE, para as diferentes populações e espaçamentos entre linhas de cultivo e interação significativa entre população e espaçamento. Contudo, verificou-se, na fase do enchimento de grãos, aos 66 DAE, que a redução do espaçamento entre linhas de cultivo aumentou a massa seca de folhas e massa seca das hastes e ramos (Figura 3). Isso provavelmente ocorreu devido a menor incidência de radiação solar direta nas plantas, prolongando a atividade fisiológica dessas plantas, retardando a senescência e aumentando a produção de massa seca na fase final do ciclo de desenvolvimento. Além disso, esse comportamento também indica que o acúmulo de

massa seca nas plantas de feijoeiro do tipo II foi pouco influenciado pelo espaçamento das plantas nas entre linhas nos estádios iniciais do ciclo. QUINTERO (1986) e STONE \& PEREIRA (1994b) também observaram que a massa seca aumenta com a redução no espaçamento das entre linhas, para cultivares do tipo II.

Os resultados semelhantes da massa seca da parte aérea das plantas observados para as diferentes populações de plantas indicam que, a massa seca resultante do maior número de plantas por unidade de área, nas maiores populações, foi compensado por uma maior massa individual das plantas nas populações menores. ARF et al. (1996) observaram resultados semelhantes e salientam que as cultivares de feijão do tipo II, em populações mais elevadas, possuem massa individual menor por serem afetadas pela competição por luz, água, nutrientes e espaço físico.

\section{CONCLUSÕES}

Populações de plantas de 175 a 325 mil plantas há ${ }^{-1}$ e espaçamento entre linhas de cultivo de 35 a $65 \mathrm{~cm}$ não ocasionam alterações no rendimento de grãos da cultivar de feijoeiro BR-FEPAGRO 44 Guapo brilhante (tipo II) irrigado por aspersão.

O número de vagens por planta e de sementes por vagem do feijoeiro irrigado (cultivar BR- FEPAGRO 44 - Guapo brilhante) apresentam elevada plasticidade, compensando o rendimento de grãos de menores populações com maior rendimento médio por planta.

A partir do estádio de início de formação das vagens, menores espaçamentos entre as linhas de cultivo do feijoeiro irrigado aumentam a produção de massa seca da parte aérea das plantas do feijoeiro. 


\section{REFERÊNCIAS BIBLIOGRÁFICAS}

ABREU, A. de F.B. Avaliação de progénies de feijoeiro do cruzamento 'Carioca 80' $x$ 'Rio Tibagi' em diferentes densidades de plantio. Lavras, 1989. 63p. Dissertação (Mestrado em Engenharia Agrícola) - ESAL, Universidade Federal de Lavras, 1989.

ADAMS, M.W. Basis of yield component compensation in crop plants with special reference to the field bean, (Phaseolus vulgaris L.). Crop Science, Madison, v.7, p.505-510,1967.

ADAMS, P.D., WEAVER, D.B. Brachytic stem irait, row spacing, and plant population effects on soybean yield. Crop Science, Madison, v.38, p.750-754,1998.

ALCÂNTARA, J.P., RAMALHO, M.A.P., ABREU, A.F.B., $e$ al. Avaliação de cultivares de feijão (Phaseolus vulgaris $\mathbf{L}$.) em diferentes densidades de semeadura e condições de ambiente. Ciência e Prática, v.15, n.4, p.375-384,1991.

ALMEIDA, M.L.de., SANGOI, L. Manejo de cultivares de feijão de diferentes hábitos de crescimento no planalto catarinense. I. Rendimento de grãos. Ciência Rural, Santa Maria, v.24, n.3, p.513-517,1994

ARF, O., BUZETTI, S., SÁ, M.E., et al. Efeito de diferentes espaçamentos e densidades sobre os componentes produtivos do feijoeiro (Phaseolus vulgaris L.) adubado em função da área e do espaçamento entre linhas. Cultura Agronómica, Ilha Solteira, v.1, n.1, p.1-10,1992.

ARF, O., SÁ, M.E.de, -OKITA, C.S., et $\boldsymbol{a l}$. Efeito de diferentes espaçamentos e densidades de semeadura sobre o desenvolvimento do feijoeiro (Phaseolus vulgaris L.). Pesquisa Agropecuária Brasileira. Brasília, v.31, n.9, p.629-634,1996.

BENNET, J.P., ADAMS, M.W., BURGA, C. Pod yield component variation and intercorrelation in (Phaseolus vulgaris L.) as affected by planting density. Crop Science. Madison, v.17, n.1, p.73-75, 1977.

BRANDES, D., VIEIRA, C., MAESTRI, M., et al Efeito da população de plantas e da época de plantio no crescimento do feijoeiro (Phaseolus vulgaris L.) II - Análise de crescimento. Experientiae, Viçosa, v.15, n.1, p.1-21,1972.

BUZETTI, S., ROMERO, P.J.M., ARF, O., et al Efeito da adubação nitrogenada em componentes da produção do feijoeiro (Phaseolus vulgaris L.) cultivado em diferentes densidades. Cultura Agronómica, nhã Solteira, v.1, p. 1119,1992 .

COMISSÃO DE FERTILIDADE DO SOLO - RS/SC Recomendações da adubação e calagem para os Estados do Rio Grande do Sul e de Santa Catarina. 3 ed. Passo Fundo: SBCS - Núcleo Regional SuVEMBRAPA-CNPT, 1995. 223p.

COSTA, J.G.C., SHBATA, J.K., COLIN, S.M. Plasticidade no feijoeiro comum. Pesquisa Agropecuária Brasileira, Brasília, v.18, n.2, p.159-167,1983.

DARIVA, T., JOBIM, J.D.C., SILVA, M.I. Efeito do espaçamento e da densidade de plantio sobre o rendimento de grãos na cultura do feijão (Phaseolus vulgaris L.). Revista do Centro de Ciências Rurais, Santa Maria, v.5, n.4, p.259$263,1975$.

DOORENBOS, J., KASSAN, A.H. Effectos dei água el rendimento de los cultivos. Roma : FAO, 1979. 212p. (Riego y drenage, 33).
EDJE, O.T., MUCHOCHO, L.K., AYONOADU, U.W.U. Bean yield and yield components as affected by fertilizer and plant population. Turrialba, São José, v.25, p 79-84,1975.

FARIA, R.T., KRANTZ, W.M. Determinação de espaçamentos e densidades adequadas para cultivares de diferentes portes, hl: REUNIÃO NACIONAL DE PESQUISA DO FEUÃO, 1, 1982, Goiânia. Anais... Goiânia : EMBRAPA-CNPAF, 1982. 427p. p. $118-119$

PRONZA, V. Resposta de cultivares de feijão (Phaseolus vulgaris L.) de porte ereto a espaçamentos entre linhas e níveis de adubação. Revista Ceres, Viçosa, v.41, n.235, p. 17-326,1994.

GOULDEN, D.S. Effects of plant population and row spacing on yield and components of yield of Navy beans (Phaseolus vulgaris L.) New Zealand Joumal of Experimental Agriculture, Weilington, v.4, p.177-180,1976.

GRAFTON, K.F., SHNEITER, A.A., NAGLE, B.J. Row spacing, plant population, and genotype $\mathrm{x}$ row spacing interaction effects on yield and yield components of dry bean. Agronomy Journal, v.80, p.631-634,1988.

KUENEMAN, E.A., SANDSTED, R.F., WALLACE, D.H., $\boldsymbol{e}$ t al Effect of plant arrangements and densities on yields of dry beans. Agronomy Journal, Madison, v.71, p.419-424,1979.

LUCAS, E.O., MILBOURN, G.M. The effect of density of planting on the growth of two (Phaseolus vulgaris L.) varieties in England. Journal of Agricultura! Science, Cambridge, v.87, p.88-89,1976.

MORENO, J.A. Clima do Rio Grande do Sul. Porto Alegre: Secretaria da Agricultura, 1961. 42p.

NIENHUIS, J., SINGH, S.P. Effects of location and plant density on yield and architectural traits in dry beans. Crop Science, v.25, n.4, p.579-584,1985

QUINTERO, E. La densidad de poblacion y distribución espacial en el crescimento y rendimento dei frijol común (Phaseolus vulgaris L.). Cultivos Tropicales, v.8, n.1, p.23-32,1986.

SANDOVAL-AVILA, D.M., MICHAELS, T.E., MURPHY, S., et al. Effect of tiliage pracnce and planting panem on performance of white bean (Phaseolus vulgaris L.) in Ontario. Canadian Journal of Plant Science, v.74, p.801805,1994 .

SHBLES, R.M., WEBER, C.R. taterception of solar radiation and dry matter production by various soybean planting pattems. Crop Science, Madison, v.6, p.55-59,1966.

SILVEIRA， J.S.M., CAETANO, L.F., FERRÃO, M.A.G. Espaçamento e densidade de plantio na cultura do feijão (Phaseolus vulgaris L.), em condições irrigadas no Estado do Espírito Santo, to: REUNIÃO SOBRE FEUÃO IRRIGADO, 1988, Goiânia. Anais... Goiânia : EMBRAPA-CNPAF, 1988. 389p. p.165-167.

STONE, L.F., PEREIRA, A.L. Sucessão arroz-feijão irrigados por aspersão. Efeitos de espaçamento entre linhas, adubação e cultivar na produtividade e nutricão do feijoeiro. Pesquisa Agropecuária Brasileira, Brasília, v.29, n.4, p.521-533, 1994a.

STONE, L.P., PEREIRA, A.L. Sucessão arroz-feijão irrigados por aspersão. Efeitos de espaçamento entre linhas, adubação e cultivar no crescimento, desenvolvimento radicular e consumo d'água do feijoeiro. Pesquisa Agropecuária Brasileira, Brasília, v.29, n.6, p.939-954,1994b 
THOMÉ, V.M.R., WESTPHALEN, S.L. Efeito de época de feijoeiro. Revista Ceres, Viçosa, v.15,n.83,p.44-53, 1968. semeadura, espaçamento entre fileiras e densidade de plantas sobre o rendimento de grãos em feijoeiro. Agronomia WESTERMANN, D.T., CROTHERS, S.E. Plant population Suiriograndense, Porto Alegre, v. 24, n. 1, p.3-29,1988 effects on the seed yield components ofbeans. Crop Science, Madison, v. 17, p.493-496,1977.
VIEIRA, C. Efeitos da densidade de plantio sobre a cultura do feijoeiro. Revista Ceres, Viçosa, v.15, n.83, p.44-53, 1968.

WESTERMANN, D.T., CROTHERS, S.E. Plant population effects on the seed yield components of beans. Crop Science, Modison, v.17, p.493-496, 1977.

Ciência Rural, v. 30, n. 4, 2000. 